\title{
Quality of life and clinical correlates in older adults living in the community and nursing homes in Macao
}

Running head: Quality of life in older adults

${ }^{1 \#}$ Kenny, C. F. Kuok, Msc

${ }^{2 \#} \mathrm{Lu} \mathrm{Li}, \mathrm{MSC}$

$2^{*}$ Yu-Tao Xiang, MD, PhD

$1,3^{*}$ Bernice O.C. Lam Nogueira, PhD

${ }^{4,5}$ Gabor S. Ungvari, MD, PhD

${ }^{6}$ Chee H. Ng, MD,

${ }^{7}$ Helen F. K. Chiu, FRCPsych,

${ }^{3}$ Linda, Tran, BA

${ }^{1}$ LI-Rong Meng, MD, PhD

1. School of Health Sciences, Macao Polytechnic Institute Macao SAR, China;

2. Macao Sino-Portuguese Nurses Association, Macao SAR, China;

3. Unit of Psychiatry, Faculty of Health Sciences, University of Macau, Macao SAR, China;

4. University of Notre Dame Australia / Marian Centre, Perth, Australia;

5. School of Psychiatry \& Clinical Neurosciences, University of Western Australia, Perth, Australia;

6. Department of Psychiatry, University of Melbourne, Melbourne, Victoria, Australia;

7. Department of Psychiatry, Chinese University of Hong Kong, Hong Kong SAR, China

\# These authors equally contributed to this work.

* Address correspondence to Dr. Yu-Tao Xiang, 3/F, Building E12, Faculty of Health Sciences, University of Macau, Avenida da Universidade, Taipa, Macau SAR, China. Fax: +853-2288-2314; Phone: +853-8822-4223; E-mail: xyutly@gmail.com; or Dr. Bernice O.C. Lam Nogueira, School of Health Sciences, Macao Polytechnic Institute, Macau SAR, China. Phone: +853- 8599-3449; E-mail: lamnog@ipm.edu.mo

This is the author manuscript accepted for publication and has undergone full peer review but has not been through the copyediting, typesetting, pagination and proofreading process, which may lead to differences between this version and the Version of Record. Please cite this article as doi: $10.1111 /$ psyg. 12214

This article is protected by copyright. All rights reserved. 


\section{ABSTRACT}

Background: No previous studies of quality of life (QOL) in Macao older adults have been done. This study aimed to examine QOL in relation to the sociodemographic and clinical characteristics in older adults aged $>50$ years in Macao.

Methods: A sample of 451 subjects (203 living in the community and 248 living in nursing homes) was interviewed using standardized instruments. Basic socio-demographic and clinical data including QOL were collected.

Result: There were no significant differences between the community and nursing home groups in all QOL domains. Multiple linear regression analyses revealed that poor physical QOL was significantly predicted by severe depressive symptoms, insomnia, major medical conditions, unmarried status and lower education $\left(F_{(11,438)}=26.2, p<0.001\right)$, which accounted for $38.2 \%$ of the variance. Poor psychological QOL was significantly predicted by severe depressive symptoms and lower educational level $\left(F_{(11,438)}=24.3, p<0.001\right)$, which accounted for $36.4 \%$ of the variance. Poor social QOL was significantly predicted by severe depressive symptoms, male gender and unmarried status $\left(F_{(11,438)}=5.6, p<0.001\right)$, which accounted for $12.5 \%$ of the variance. Poor environment QOL was significantly predicted by lower educational level, severe depressive symptoms, and advanced age $\left(F_{(11,438)}=6.6, p<0.001\right)$, which accounted for $12.1 \%$ of the variance. 
Conclusion: Macao older adults had poorer scores on physical and social QOL domains in comparison with the corresponding scores for Chinese general population. Their QOL was more strongly related to severe depressive symptoms, major medical conditions and insomnia.

Keywords: older adults, quality of life, depressive symptoms

\section{INTRODUCTION}

Macao has been a Special Administrative Region of China in 1999 after four century of Portugal administration. Behind the westernized facade, traditional Chinese habits, values and principles, mostly Confucian in nature, remains influential in Macao. Latest statistics released by the Macao Government showed that in 2015 Macao's population was about 0.64 million and the life expectancy was 84.4 years old.

In recent years the proportion of aging population has been increasing worldwide. The world's population aged 60 years and over has reached 900 million in 2015 and the figure is expected to reach two billion by $2050 .{ }^{1}$ In Macao the percentage of older adults aged 65 years and above was $8.4 \%$ in 2015 and the figure is expected to reach $20.7 \%$ by $2036,{ }^{2}$ indicating Macau has become an "aging society".

In the past decades qualify of life (QOL) has become an important outcome measure because it can give a more comprehensive view of health care. ${ }^{3}$ The World Health Organization (WHO) defined QOL as individuals' perception of 
their position in life in the context of the culture and value systems in which they live and in relation to their goals, expectations, standards and concerns. 4,5 QOL includes physical health, psychological, social relationships and environment domains. ${ }^{6}$

Aging is significantly associated with a number of negative outcomes, such as poor mental health, physical comorbidities, poor coping abilities, impaired functioning and cognitive performance, and bereavement, 7,8 which may lead to lower QOL. In order to develop appropriate interventions for improving care quality, it is important to examine QOL and related socioeconomic and clinical correlates in older adults.

Commonly reported correlates of lower QOL in older adults included advanced age, lower education, depression, loneliness, lack of social support, poor financial status, physical comorbidities. ${ }^{9-12}$ Evidence suggested that cross-cultural or ethnic differences with respect to QOL exist. ${ }^{13}$ It should be noted that most studies examining $\mathrm{QOL}$ in older adults were conducted in Western countries where the prevailing Judeo-Christian culture places high value on independence and self-realization. ${ }^{14}$ In Chinese societies including Macao, Confucian values that emphasize interdependence and group harmony within the family predominate. ${ }^{15}$ Therefore, it is unlikely that findings obtained Western-settings can be applicable to Macao.

This study aimed to determine the QOL in older adults aged 50 years and over in Macao and examine its independent socio-demographic and clinical 
correlates. Both community-dwelling older adults and nursing home residents were involved in this study.

\section{METHODS}

Study sêtting and participants

This is a cross-sectional study conducted between September 1 and November 31, 2015 in Macao. Of the 20 nursing homes in Macao, 11 were randomly selected based on a computer-generated random number table. All the residents in the selected nursing homes were approached and invited to participate in the study. Residents living in the community were consecutively recruited in the same districts. The inclusion criteria included (1) age of 50 years or above, (2) Chinese ethnicity and being fluent in Chinese language (Cantonese or Mandarin), and (3) having ability to communicate adequately and complete the interview. The age cutoff of older adults varied from 50 to 65 years across Asian countries and territories according to local cultural and professional traditions. In this survey those aged $>/=50$ years were defined as 'older adults'. The same age cutoff was also used in WHO reports and other studies. ${ }^{16-19}$ The study protocol was approved by the clinical research ethics committee of Macau Polytechnic Institute. All participants provided written informed consent.

Assessment instruments and evaluation 
Participants' socio-demographic and clinical characteristics were recorded using a standardized form designed for this study. The interview which lasted around 30-50 minutes was conducted by trained research assistants.

The presence and severity of depressive symptoms in the past week were measured with the Chinese version of the Patient Health Questionnaire (PHQ9) total score that consists of nine items. ${ }^{16,20-22}$ The PHQ-9 is a self-reported scale and scores of each item range from 0 (not at all) to 3 (nearly every day) with a total score between 0 and 27. A higher score indicates more severe depressive symptoms. QOL was measured using the Chinese version of the World Health Organization Quality of Life-BREF (WHOQOL-BREF). 6,23 The WHOQOL-BREF consists of 26 items covering four domains: physical health, psychological health, social relationships and environmental factors. A higher score indicates a better QOL.

The presence of three basic forms of insomnia during the past week was examined by asking three questions: 24,25 "Do you have difficulties in falling sleep?" for difficulty initiating sleep (DIS); "Do you have the difficulties in maintaining sleep and wake up often?" for difficulty maintaining sleep (DMS); and "Do you wake up in the midnight or early morning and have difficulties in falling sleep again? for early morning awakening (EMA). If a participant answered "often" to any of the three questions, he or she was rated as "having insomnia". This assessment of insomnia was also used in other studies. ${ }^{24-27}$ 
The inter-rater reliability of the definition of insomnia between the research assistants obtained in 20 older adults was satisfactory (kappa values $>0.9$ ).

\section{Statistical analysis}

Data was analyzed using SPSS 20.0 for Windows. The comparison between the community and nursing home groups with regard to basic demographic and clinical characteristics were performed by independent sample t-test, MannWhitney $\mathrm{U}$ test, and Chi-square test, as appropriate. QOL were compared between the community and nursing home groups with analysis of covariance (ANCOVA) after controlling for the potentially confounding effects of variables that significantly differed between the two groups in above univariate analyses. One-sample t-test was used to compare the QOL scores in this study with for the normative data for the Hong Kong general population. As normative data of QOL was not available in Macao, the normative data for the Hong Kong general population was used as the reference due to similarities in historical, socioculturał and economic contexts between Hong Kong and Macao. Multiple linear regression analysis with the "enter" method was used to determine the independent relationships between socio-demographic and clinical characteristics and QOL. Each QOL domains was the dependent variable separately, while demographic and clinical variables including age, gender, marital status, living with others, living in nursing home, education, household income, religious beliefs, insomnia, major medical conditions and the PHQ-9 
total score were entered as the independent variables. The one-sample Kolmogorov-Smirnov test was used to check the normal distribution of continuous variables. In an attempt to avoid multi-collinearity, tolerance was used to measure the strength of linear relationships among the independent variableș; al value of 0.6 or above was regarded as acceptable. The level of significance was set at 0.05 (two-tailed).

\section{RESULT}

Out of a total of 570 older adults, 541 (203 from the community and 248 from nursing homes) met the study criteria and completed the interview, giving a participation rate of $94.9 \%$. Table 1 presents the socio-demographic and clinical characteristics of the whole sample, and the comparison between the community and nursing home groups. Compared to those from nursing homes, the participants in the community are more likely to be younger, male gender, be married, live with others, have higher education level and higher household income and less likely to have religion beliefs, major medical condition, insomnia and depressive symptoms. After controlling for the potential confounding effects of the above variables that significantly differed between the two groups in univariate analysis, there was no significant difference between the two groups in in physical $\left(F_{(11,450)}=0.1, p=0.69\right)$, psychological $(F$ $(11,450)=0.5, \mathrm{p}=0.44)$, social $\left(\mathrm{F}_{(11,450)}=1.2, \mathrm{p}=0.25\right)$ and environmental $\mathrm{QOL}(\mathrm{F}$ $(11,450)=0.002, \mathrm{p}=0.96)$. 
The physical and psychological domains of QOL in the older adults in Macao had significantly poorer scores in comparison with the normative data obtained for the Hong Kong Chinese general population. ${ }^{28}$ However, there was no significant difference in the social and environmental QOL domains between both cohorts (Table 2).

Table 3 shows that poor physical QOL was significantly predicted by severe depressive symptoms, insomnia, major medical conditions, unmarried status and lower education $\left(F_{(11,438)}=26.2, p<0.001\right)$, which accounted for $38.2 \%$ of the variance. Poor psychological QOL was significantly predicted by severe depressive symptoms and lower educational level $\left(F_{(11,438)}=24.3, p<0.001\right)$, which accounted for $36.4 \%$ of the variance. Poor social QOL was significantly predicted by severe depressive symptoms, male gender and unmarried status $\left(F_{(11,438)}=5.6, p<0.001\right)$, which accounted for $12.5 \%$ of the variance. Poor environment QOL was significantly predicted by lower educational level, severe depressive symptoms, and advanced age $\left(F_{(11,438)}=6.6, p<0.001\right)$, which accounted for $12.1 \%$ of the variance.

\section{DISCUSSION}

This is the first study examining QOL and its independent demographic and clinical correlates in older adults in Macao. Given the differences between community-dwelling and nursing home residents we assume that older adults in the community would have a higher QOL than those living nursing homes. 
However, no differences in all QOL domains were observed in both univariate and multivariate analyses. This unexpected result could be partly explained by the distress/protection $\mathrm{QOL}$ model: ${ }^{29} \mathrm{QOL}$ is determined by an interaction between protective factors (e.g., good living conditions and social support) and distressing factors (e.g., poor physical health and low income). QOL increases if protective factors predominate over distress factors. In this study, compared to those living in the community, older adults in nursing homes had more comfortable living conditions, such as stable food supply and good healthcare service, which may increase their QOL and thus minimize the differences between both groups.

As expected, older adults in Macao had significantly poorer scores in physical and social QOL domains in than those of the general population. In this study, $87.7 \%$ of older adults had major medical conditions. Compared to young adults, older adults do not only experience the distressing symptoms of major medical conditions but also suffer the burden of diseases and impaired functioning, ${ }^{30,31}$ e.g. being insufficient in self-care and lack of recreation activities. According to the satisfaction QOL model, ${ }^{32}$ these unmet basic social needs could lead to poor QOL. Contrary to our expectation, no statistically significant difference between older adults and the Hong Kong Chinese general population in social and environmental QOL was found in this study. Apart from the dated normative population data, ${ }^{28}$ another explanation may relate to increased acceptance impaired functioning and poor physical health. As a 
result, their QOL, such as in social and environmental domains, may be higher than before even if their physical health has not improved greatly. ${ }^{7,33}$ Further studies in Macao older adults to confirm or refute these results are warranted.

Consisted with other studies, ${ }^{7}$ depressive symptoms were negatively associated with all QOL domains, indicating the important role depressive symptoms played in contributing to QOL. Similar to earlier findings, ${ }^{12}$ older adults having major medical conditions and insomnia usually had a lower QOL as we found in this study. Married people usually have better social support and care when they suffer from physical diseases compared to those who are unmarried, 34,35 which could explain the positive associations between married marital status and better physical and social QOL. Education was positively associated with physical, psychological and environmental QOL, which is consistent with earlier findings ${ }^{10}$. Lower education is usually related to unhappiness, poor social relationships and poor self-assessed health, ${ }^{36}$ which may decrease QOL.

Prior findings showed that female gender and advanced age were associated with less access to information, poor economic status and more loneliness, ${ }^{37,38}$ which could lower QOL. However, in this study male gender was negatively associated with lower social QOL and advanced age positively associated with higher environmental QOL. We have no explanation for these unexpected findings which need to be replicated in future studies. 
The results of this study should be interpreted with caution due to several limitations. First, due to the cross-sectional design of the survey, the causality between QOL and other variables could not be identified. Second, more information related to $\mathrm{QOL}$, such as coping style, self-esteem and social support, were not collected. Finally, as QOL values for the general population in Macao was unavailable, the normative data obtained for the Hong Kong general population was used.

In conclusion, Macao older adults had poorer scores on physical and social QOL domains in comparison with the corresponding scores for Chinese general population. The adverse impact of depressive symptoms, major medical conditions and insomnia on $\mathrm{QOL}$ in Macao older adults suggests that therapeutic interventions addressing these problems may be of considerable benefit in improving their QOL.

\section{Acknowledgements}

This study was funded by a grant from Macao Polytechnic Institute, Macao (RP/ESS-05/2015). The authors thank colleagues in Caritas Macau, Macao Sino-Portuguese Nurses Association, Seniors Academy of Macao Polytechnic Institute and other organizations involved and all participants in this study. The authors are grateful to project helpers in Nursing School at Macao Polytechnic Institute for their contributions to the data collection and dataset 
establishment.

\section{Conflict of Interest Statement}

The authors declare no conflicts of interest concerning this article.

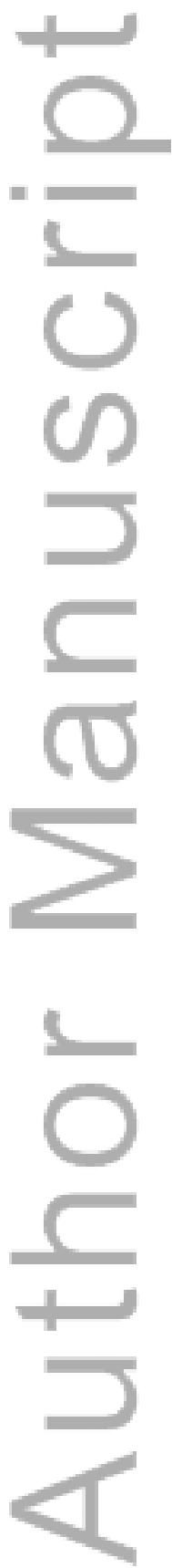

This article is protected by copyright. All rights reserved. 


\section{REFERENCE}

1. WHO. World health statistic 2015; 2015.

2. The Government Information Bureau of the Macao. Macao Yearbook 2015: The Government Information Bureau of the Macao; 2015.

3. Käplan RM. Quality of life: an outcomes perspective. Archives of physical medicine and rehabilitation 2002; 83: S44-50.

4. Fitzgerald $\mathrm{PB}$, Williams $\mathrm{CL}$, Corteling $\mathrm{N}$, et al. Subject and observer-rated quality of life in schizophrenia. Acta psychiatrica Scandinavica 2001; 103: $387-392$.

5. WHO. The World Health Organization Quality of Life assessment (WHOQOL): position paper from the World Health Organization. Social science \& medicine (1982) 1995; 41: 1403-1409.

6. WHO. Development of the World Health Organization WHOQOL-BREF quality of life assessment. The WHOQOL Group. Psychol Med 1998; 28: 551558.

7. Sivertsen H, Bjorklof GH, Engedal K, Selbaek G, Helvik AS. Depression and Quality of Life in Older Persons: A Review. Dement Geriatr Cogn Disord 2015; 40: 311-339.

8. Kanauchi M, Kubo A, Kanauchi K, Saito Y. Frailty, health-related quality of life and mental well-being in older adults with cardiometabolic risk factors. Int J Clin Pract 2008; 62: 1447-1451. 
9. Bowling A. Ageing Well : Quality of Life in Old Age. Maidenhead: Open University Press; 2005.

10. Tajvar M, Arab M, Montazeri A. Determinants of health-related quality of life in elderly in Tehran, Iran. BMC Public Health 2008; 8: 323.

11. Arslantas H, Adana F, Abacigil Ergin F, Kayar D, Acar G. Loneliness in Elderly People, Associated Factors and Its Correlation with Quality of Life: A Field Study from Western Turkey. Iranian journal of public health 2015; 44: 43-50.

12. Lo CM, Lee PH. Prevalence and impacts of poor sleep on quality of life and associated factors of good sleepers in a sample of older Chinese adults. Health Qual Life Outcomes 2012; 10: 72.

13. Warner R, de Girolamo G, Belelli G, Bologna C, Fioritti A, Rosini G. The quality of life of people with schizophrenia in Boulder, Colorado, and Bologna, Italy. Schizophrenia bulletin 1998; 24: 559-568.

14. Chan GW, Ungvari GS, Shek DT, Leung Dagger JJ. Hospital and community-based care for patients with chronic schizophrenia in Hong Kong-quality of life and its correlates. Soc Psychiatry Psychiatr Epidemiol 2003; 38: 196-203.

15. Tan HY, Choo WC, Doshi S, Lim LE, Kua EH. A community study of the health-related quality of life of schizophrenia and general practice outpatients in Singapore. Social psychiatry and psychiatric epidemiology 2004; 39: 106112. 
16. Dassori AM, Copeland LA, Zeber JE, Miller AL. Factors in secondgeneration antipsychotic switching patterns in a national sample of older veterans with schizophrenia. Psychiatric services (Washington, DC) 2011; 62: 47-53.

17. Xiăng YT, Buchanan RW, Ungvari GS, et al. Use of clozapine in older Asian patients with schizophrenia between 2001 and 2009. PloS one 2013; 8: e66154.

18. Xiang YT, Li Y, Correll CU, et al. Common use of high doses of antipsychotic medications in older Asian patients with schizophrenia (20012009). Int J Geriatr Psychiatry 2013.

19. WHO. Information Needs for Research, Policy and Action on Ageing and Older Adults, 2001.

20. Kroenke K, Spitzer RL, Williams JB. The PHQ-9: validity of a brief depression severity measure. J Gen Intern Med 2001; 16: 606-613.

21. Kroenke K, Spitzer RL, Williams JB. The Patient Health Questionnaire-2: validity of a two-item depression screener. Med Care 2003; 41: 1284-1292.

22. Chen S, Chiu H, Xu B, et al. Reliability and validity of the PHQ-9 for screening late-life depression in Chinese primary care. Int J Geriatr Psychiatry 2010; 25: 1127-1133.

23. Fang JQ, Hao YT, Li CX. Reliability and validity for Chinese version of WHO quality of life scale (in Chinese). Chinese Mental Health Journal 1999;

13: 203-205. 
24. Liu X, Uchiyama M, Okawa M, Kurita H. Prevalence and correlates of selfreported sleep problems among Chinese adolescents. Sleep 2000; 23: 27-34.

25. Liu X, Zhou H. Sleep duration, insomnia and behavioral problems among Chinese adolescents. Psychiatry Res 2002; 111: 75-85.

26. Chiu HF, Leung T, Lam LC, et al. Sleep problems in Chinese elderly in Hong Kong. Sleep 1999; 22: 717-726.

27. Guo L, Deng J, He Y, et al. Prevalence and correlates of sleep disturbance and depressive symptoms among Chinese adolescents: a crosssectional survey study. BMJ Open 2014; 4: e005517.

28. Hong Kong Project Team. Hong Kong Chinese Version World Health Organization Quality of Life Measure-abbreviated version. Hong Kong: Hong Kong Project Team.; 1997.

29. Ritsner M, Modai I, Endicott J, et al. Differences in quality of life domains and psychopathologic and psychosocial factors in psychiatric patients. The Journal of clinical psychiatry 2000; 61: 880-889; quiz 890.

30. Feng $\mathrm{L}$, Yap KB, Ng TP. Depressive symptoms in older adults with chronic kidney disease: mortality, quality of life outcomes, and correlates. The American journal of geriatric psychiatry : official journal of the American Association for Geriatric Psychiatry 2013; 21: 570-579.

31. Ho C, Feng L, Fam J, Mahendran R, Kua EH, Ng TP. Coexisting medical comorbidity and depression: multiplicative effects on health outcomes in older adults. International psychogeriatrics / IPA 2014; 26: 1221-1229. 
32. Angermeyer MC, Kilian R. Theoretical models of quality of life for mental disorders. New York: Wiley; 1997.

33. McDowell I. General Health Status and Quality of Life; Measuring Health. A Guide to Rating Scales and Questionnaires. Oxford, 2006.

34. Walker A. Understanding quality of life in old age Open University Press 2005.

35. Thanakwang K. Family support, anticipated support, negative interaction, and psychological well-being of older parents in Thailand. Psychogeriatrics 2015; 15: 171-178.

36. Lasheras C, Patterson AM, Casado C, Fernandez S. Effects of education on the quality of life, diet, and cardiovascular risk factors in an elderly Spanish community population. Exp Aging Res 2001; 27: 257-270.

37. Savikko N, Routasalo P, Tilvis RS, Strandberg TE, Pitkala KH. Predictors and subjective causes of loneliness in an aged population. Archives of gerontology and geriatrics 2005; 41: 223-233.

38. Liu $L J$, Guo Q. Loneliness and health-related quality of life for the empty nest elderly in the rural area of a mountainous county in China. Quality of life research : an international journal of quality of life aspects of treatment, care and rehabilitation 2007; 16: 1275-1280. 
Table1 Basic demographic and clinical characteristics of the whole sample

\begin{tabular}{|c|c|c|c|c|c|c|c|c|c|}
\hline & \multicolumn{2}{|c|}{$\begin{array}{c}\text { Total sample } \\
(n=451)\end{array}$} & \multicolumn{2}{|c|}{$\begin{array}{c}\text { Community } \\
(n=203)\end{array}$} & \multicolumn{2}{|c|}{$\begin{array}{l}\text { Nursing home } \\
(n=248)\end{array}$} & \multicolumn{3}{|c|}{ Statistics } \\
\hline & $\mathbf{N}$ & $\%$ & $\mathbf{N}$ & $\%$ & $\mathbf{N}$ & $\%$ & $x^{2}$ & df & $p$ \\
\hline Male & 96 & 21.3 & 61 & 30.0 & 35 & 14.1 & 16.9 & 1 & $<0.001$ \\
\hline Married/cohabitating & 213 & 47.2 & 148 & 72.9 & 65 & 26.2 & 97.6 & 1 & $<0.001$ \\
\hline Living with others & 349 & 77.4 & 186 & 91.6 & 163 & 65.7 & 42.7 & 1 & $<0.001$ \\
\hline Education & & & & & & & 98.9 & 1 & $<0.001$ \\
\hline Illiterate or primary school & 274 & 60.8 & 72 & 35.5 & 202 & 81.5 & & & \\
\hline Junior high school and above & 177 & 39.2 & 131 & 64.5 & 46 & 18.5 & & & \\
\hline Religious beliefs & 285 & 63.2 & 114 & 56.2 & 171 & 69.0 & 7.8 & 1 & 0.005 \\
\hline $\begin{array}{l}\text { Household monthly income } \\
\text { (MOP) < } 10000 \text { MOP }\end{array}$ & 372 & 82.7 & 137 & 67.5 & 235 & 95.1 & 59.4 & 1 & $<0.001$ \\
\hline Major medical conditions & 396 & 87.8 & 171 & 84.2 & 225 & 90.7 & 4.3 & 1 & 0.03 \\
\hline Any type of insomnia & 172 & 38.1 & 62 & 13.7 & 110 & 44.4 & 9.0 & 1 & 0.003 \\
\hline & Mean & SD & Mean & SD & Mean & SD & $T / Z$ & df & \\
\hline Age (years) & 72.0 & 10.5 & 64.1 & 6.8 & 78.4 & 8.3 & -19.3 & 449 & $<0.001$ \\
\hline PHQ-9 & 4.5 & 4.3 & 2.8 & 2.9 & 5.9 & 4.7 & -7.7 & $--^{a}$ & $<0.001$ \\
\hline Physical QOL & 13.7 & 2.5 & 14.6 & 2.2 & 13.0 & 2.6 & 0.1 & 449 & 0.69 \\
\hline Psychological QOL & 13.8 & 2.4 & 14.6 & 2.2 & 13.2 & 2.4 & 0.5 & 449 & 0.44 \\
\hline Social QOL & 14.2 & 2.5 & 14.4 & 2.3 & 14.0 & 2.6 & 1.2 & 449 & 0.25 \\
\hline Environmental QOL & 13.6 & 2.0 & 13.7 & 2.0 & 13.5 & 2.0 & 0.002 & 449 & 0.96 \\
\hline
\end{tabular}

Bold values are $p<0.05$; a=Mann-Whitney $U$ test; 1 USD=8.0 MOP; PHQ-9=Patient Health Questionnaire-9; $\mathrm{QOL}=$ quality of life

This article is protected by copyright. All rights reserved. 
Table 2. Comparison of QOL between the Macao study data and normative data from Hong Kong Chinese general population

\begin{tabular}{|l|c|c|c|c|}
\hline QOL domains & $\begin{array}{c}\text { Subjects (n=451) } \\
\text { Mean (SD) }\end{array}$ & $\begin{array}{c}\text { Hong Kong Chinese } \\
\text { general Population } \\
\text { Mean (SD) }\end{array}$ & $\mathrm{t}$ & $\mathrm{p}$ \\
\hline Physical & $13.7(2.5)$ & $15.85(2.13)$ & -17.2 & $<0.001$ \\
\hline Psychological & $13.8(2.4)$ & $14.77(2.39)$ & -7.7 & $<0.001$ \\
\hline Social & $14.2(2.5)$ & $14.26(2.39)$ & -0.3 & 0.71 \\
\hline Environment & $13.6(2.0)$ & $13.74(2.45)$ & -1.1 & 0.26 \\
\hline
\end{tabular}

${ }^{a}$ Data taken from Hong Kong Project Team ${ }^{28}$

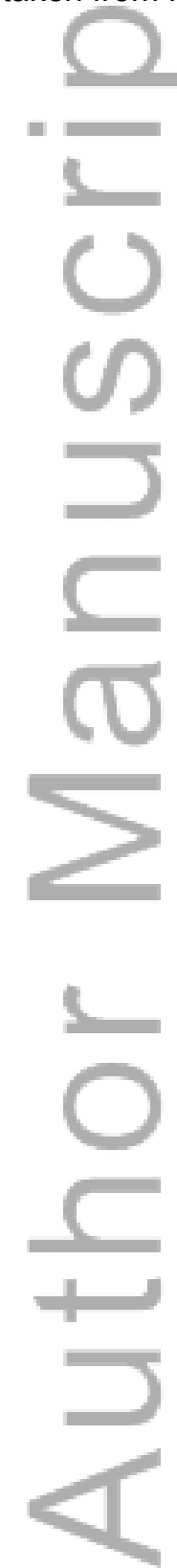

This article is protected by copyright. All rights reserved. 
Table 3. Independent socio-demographic correlates of QOL (by multiple linear regression analysis)

\begin{tabular}{|l|c|c|c|c|c|c|c|c|}
\hline & \multicolumn{2}{|c|}{ Physical } & \multicolumn{2}{c|}{ Psychological } & \multicolumn{2}{c|}{ Social } & \multicolumn{2}{c|}{ Environmental } \\
\hline & $\mathrm{B}$ & $\mathrm{P}$ & $\mathrm{B}$ & $\mathrm{P}$ & $\mathrm{B}$ & $\mathrm{P}$ & $\mathrm{B}$ & $\mathrm{P}$ \\
\hline Male & 0.18 & 0.47 & -0.06 & 0.78 & -0.94 & $\mathbf{0 . 0 0 2}$ & -0.20 & 0.39 \\
\hline Married/cohabitating & 0.53 & $\mathbf{0 . 0 3}$ & 0.48 & 0.051 & 0.94 & $\mathbf{0 . 0 0 2}$ & 0.34 & 0.15 \\
\hline Living with others & 0.22 & 0.39 & -0.20 & 0.42 & -0.24 & 0.43 & -0.22 & 0.38 \\
\hline Education & 0.55 & $\mathbf{0 . 0 1}$ & 0.43 & $\mathbf{0 . 0 4}$ & 0.42 & 0.11 & 0.61 & $\mathbf{0 . 0 0 5}$ \\
\hline Religious beliefs & 0.25 & 0.22 & -0.02 & 0.89 & -0.20 & 0.39 & -0.11 & 0.56 \\
\hline $\begin{array}{l}\text { Household monthly income } \\
\text { (MOP) < 10000 MOP }\end{array}$ & -0.22 & 0.43 & -0.24 & 0.38 & 0.32 & 0.33 & -0.02 & 0.93 \\
\hline Major medical conditions & -0.60 & $\mathbf{0 . 0 4}$ & -0.24 & 0.39 & -0.16 & 0.64 & -0.19 & 0.48 \\
\hline Any type of insomnia & -0.50 & $\mathbf{0 . 0 2}$ & -0.02 & 0.9 & -0.26 & 0.29 & -0.39 & 0.059 \\
\hline Nursing home & -0.11 & 0.69 & -0.21 & 0.44 & 0.38 & 0.25 & -0.01 & 0.96 \\
\hline & & & & & & & & \\
\hline Age (years) & -0.0001 & 0.99 & 0.007 & 0.58 & 0.01 & 0.4 & 0.04 & $<\mathbf{0 . 0 0 1}$ \\
\hline PHQ-9 & -0.29 & $<\mathbf{0 . 0 0 1}$ & -0.32 & $<\mathbf{0 . 0 0 1}$ & -0.14 & $<\mathbf{0 . 0 0 1}$ & -0.13 & $<\mathbf{0 . 0 0 1}$ \\
\hline
\end{tabular}

Bolded values are $\mathrm{p}<0.05 ; \mathrm{PHQ}-9=$ Patient Health Questionnaire-9

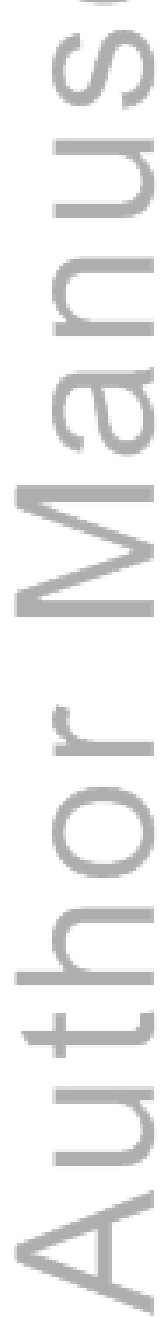

This article is protected by copyright. All rights reserved. 


\section{University Library}

\section{- M M N E R VA A gateway to Melbourne's research publications}

Minerva Access is the Institutional Repository of The University of Melbourne

\section{Author/s:}

Kuok, KCF;Li, L;Xiang, Y-T;Nogueira, BOCL;Ungvari, GS;Ng, CH;Chiu, HFK;Tran, L;Meng, L$\mathrm{R}$

Title:

Quality of life and clinical correlates in older adults living in the community and in nursing homes in Macao

Date:

2017-05-01

Citation:

Kuok, K. C. F., Li, L., Xiang, Y. -T., Nogueira, B. O. C. L., Ungvari, G. S., Ng, C. H., Chiu, H. F. K., Tran, L. \& Meng, L. -R. (2017). Quality of life and clinical correlates in older adults living in the community and in nursing homes in Macao. PSYCHOGERIATRICS, 17 (3), pp.194-199. https://doi.org/10.1111/psyg.12214.

Persistent Link:

http://hdl.handle.net/11343/292329 